\title{
Impact of the health education and preventive equipment package (HEPEP) on prevention of Strongyloides stercoralis infection among rural communities in Northeast Thailand: a cluster randomized controlled trial
}

Pokkamol Laoraksawong ${ }^{1}$, Oranuch Sanpool ${ }^{2,3}$, Rutchanee Rodpai ${ }^{2,3}$, Tongjit Thanchomnang ${ }^{3,4}$, Wanida Kanarkard ${ }^{5}$, Wanchai Maleewong ${ }^{2,3}$, Ratthaphol Kraiklang ${ }^{1,2^{*}}$ and Pewpan M Intapan ${ }^{2,3^{*}}$ (D)

\begin{abstract}
Background: Strongyloidiasis is prevalent in northeast Thailand. This study aimed to evaluate the impact of the Health Education and Preventive Equipment Package (HEPEP), a package we developed to improve awareness and aid in the prevention of Strongyloides stercoralis infection among rural communities in northeast Thailand.

Methods: This was an intervention trial conducted in 12 villages (six interventions and six controls) in rural areas of northeast Thailand from March 2016 to September 2017. Single stool sample was collected from each participant and examined using agar plate culture (APC) technique. Each participant was interviewed using a pre-tested questionnaire, treated with single dose of ivermectin $(200 \mu \mathrm{g} / \mathrm{Kg})$, and allocated to either the intervention or control group. Members of the intervention group were given "Practices to Prevent Strongyloidiasis" poster and vinyl boards containing information aimed at raising awareness of $S$. stercoralis and strongyloidiasis. In addition, they were given a poster lecture regarding the lifecycle of $\mathrm{S}$. stercoralis before being treated with ivermectin. Aside from that, they were also given a protective equipment package. Monthly refresher courses were provided by village health volunteers (VHVs) regarding the health information they had received and proper equipment usage. The control group, on the other hand, was only provided with a five-minute lecture regarding strongyloidiasis. Assessment of new infection was conducted 3 months later in 327 and 318 participants in the intervention group and control group, respectively.

Results: The HEPEP had $41 \%$ greater efficacy in preventing S. stercoralis infection in the intervention group than the measures taken in the control group (adjusted Odds Ratio $(\mathrm{aOR})=0.59 ; 95 \% \mathrm{Cl}$ : 0.41 to 0.85 , $P$-value $=0.005$ ). The intervention group also scored significantly higher on all aspects of a test of $\mathrm{S}$. stercoralis knowledge compared with the control group (mean difference (mean dif.) $=2.89, P$-value $=<0.05$ ).

(Continued on next page)
\end{abstract}

\footnotetext{
*Correspondence: ratthaphol.bc@gmail.com; pewpan@kku.ac.th

1 Department of Public Health Administration, Health Promotion, Nutrition,

Faculty of Public Health, Khon Kaen University, Khon Kaen, Thailand

2Department of Parasitology, Faculty of Medicine, Khon Kaen University,

Khon Kaen, Thailand

Full list of author information is available at the end of the article
}

(c) The Author(s). 2018 Open Access This article is distributed under the terms of the Creative Commons Attribution 4.0 International License (http://creativecommons.org/licenses/by/4.0/), which permits unrestricted use, distribution, and

reproduction in any medium, provided you give appropriate credit to the original author(s) and the source, provide a link to the Creative Commons license, and indicate if changes were made. The Creative Commons Public Domain Dedication waiver (http://creativecommons.org/publicdomain/zero/1.0/) applies to the data made available in this article, unless otherwise stated. 
(Continued from previous page)

Conclusions: The HEPEP was the first model that has been found to be effective in controlling of S. stercoralis in rural communities in the northeast Thailand. The results should encourage policy makers and public health personnel to improve control programs, as well as health promotion, with regard to parasites.

Trial registration: Thai Clinical Trials Registry (TCTR), Medical Research Foundation of Thailand, Medical Research Network of the Consortium of Thai Medical Schools: MedResNet (Thailand) (identification number: TCTR20180404002) Registered 4 April 2018 (retrospectively registered).

Keywords: Strongyloides stercoralis, Health education and preventive equipment package, Thailand

\section{Background}

Human strongyloidiasis, which is caused by infection with a parasitic nematode of the genus Strongyloides, is an important public health problem, especially in tropical and sub-tropical countries [1, 2]. Currently, more than 100 million people are infected with Strongyloides stercoralis worldwide [3-5]. Strongyloides stercoralis has a complex life cycle, which includes free-living and parasitic cycles, as well as autoinfection $[3,5,6]$. The free-living life cycle enables the parasite to persist in the surrounding environment [7]. In addition, the possibility of autoinfection, together with asymptomatic chronic infection, enables the parasite to persist in humans [7]. Moreover, autoinfection can lead to hyperinfection and disseminated strongyloidiasis [5, 7-9].

Thailand is a tropical country that has an environment suitable for $S$. stercoralis in its free-living phase. This leads to a high risk of human infection during its parasitic phrase. In the northeastern region, the prevalence of $S$. stercoralis infection has been shown to range from 2.5 to $33.3 \%$ based on community surveys [2, 10-15]. For example, an eleven-year retrospective hospital-based study showed that the prevalence of infection ranged from 11.0 to $24.3 \%$ in the northeast region [2]. Accordingly, strongyloidiasis is considered to be a helminthiasis of public health importance in Thailand requiring the development and implementation of an integrated approach to prevention and control that includes screening, mass treatment, and health education [2]. It has been recommended that these strategies should incorporate multiple interventions to maximize the sustainability of control programs [16]. This paper aimed to evaluate the impact of a Health Education and Preventive Equipment Package (HEPEP) on the prevention of $S$. stercoralis infection among rural communities in northeast Thailand.

\section{Methods}

\section{Study design}

This study was an open-label controlled trial [Thai Clinical Trials Registry (TCTR), Medical Research Foundation of Thailand, Medical Research Network of the Consortium of Thai Medical Schools: MedResNet (Thailand) (identification number: TCTR20180404002)] that aimed to evaluate the impact of the Health Education and Preventive Equipment Package on prevention and control of S. stercoralis infection among communities in northeast Thailand from March 2016 to September 2017. Participants from one area served as an experimental group, while those from another area near the first served as the control group.

\section{Study area and study population}

This study was carried out in two areas of Kalasin province in northeast Thailand: (1) Nong Bua sub-district in Nong Kung Si district (intervention group) and (2) Phu Din sub-district in Mueang Kalasin district (control group). Both areas are located near Lam Pao dam. Nong Bua sub-district is located at $16.716733^{\circ}$ latitude and $103.383900^{\circ}$ longitude and Phu Din sub-district is located at $16.643328^{\circ}$ latitude and $103.517948^{\circ}$ longitude (Fig. 1). Residents of both areas are primarily agriculturists (i.e. working in rice fields, cassava, sugarcane, and Para rubber farms) [17]. The two areas were selected based on data from previous studies showing that the province had a high prevalence of strongyloidiasis [10, 18]. The sample size was determined using the command "clustersampsi, binomial sample size" in STATA Version 10.1 (College Station, Texas: StataCorp LLC). The STATA command that was used was "clustersampsi, binomial samplesize p1(.23) p2(.10) $\mathrm{m}(30)$ rho(0.034) alpha $(0.05)$ beta(0.80)". It was calculated based on the prevalence rate $\left(\mathrm{p}_{1}\right)$ of $23.0 \%$ found in a previous study [10], a prevalence rate after added intervention $\left(\mathrm{p}_{2}\right)$ of $10.0 \%$ with a $95 \%$ confidence interval $\left(Z^{2}{ }_{\alpha / 2}=1.96\right), 80 \%$ confidence interval $\left(Z_{\beta}=0.84\right)$, design effect of 2,10 clusters per arm, and an intra cluster correlation (ICC) of 0.034. The calculated sample size was 300 per area. We assumed that the final sample size would be reduced by around $20 \%$ due to unavailability of stool on the day of collection, making the adjusted sample size 360 per area. A simple random sampling method was used to select subjects from each sub-district. Subject inclusion criteria were that participants were 1) residents of Nong Bua or Phu Din sub-district and 2) age $\geq 20$ years old. Subjects were excluded if they 1 ) had recently migrating 


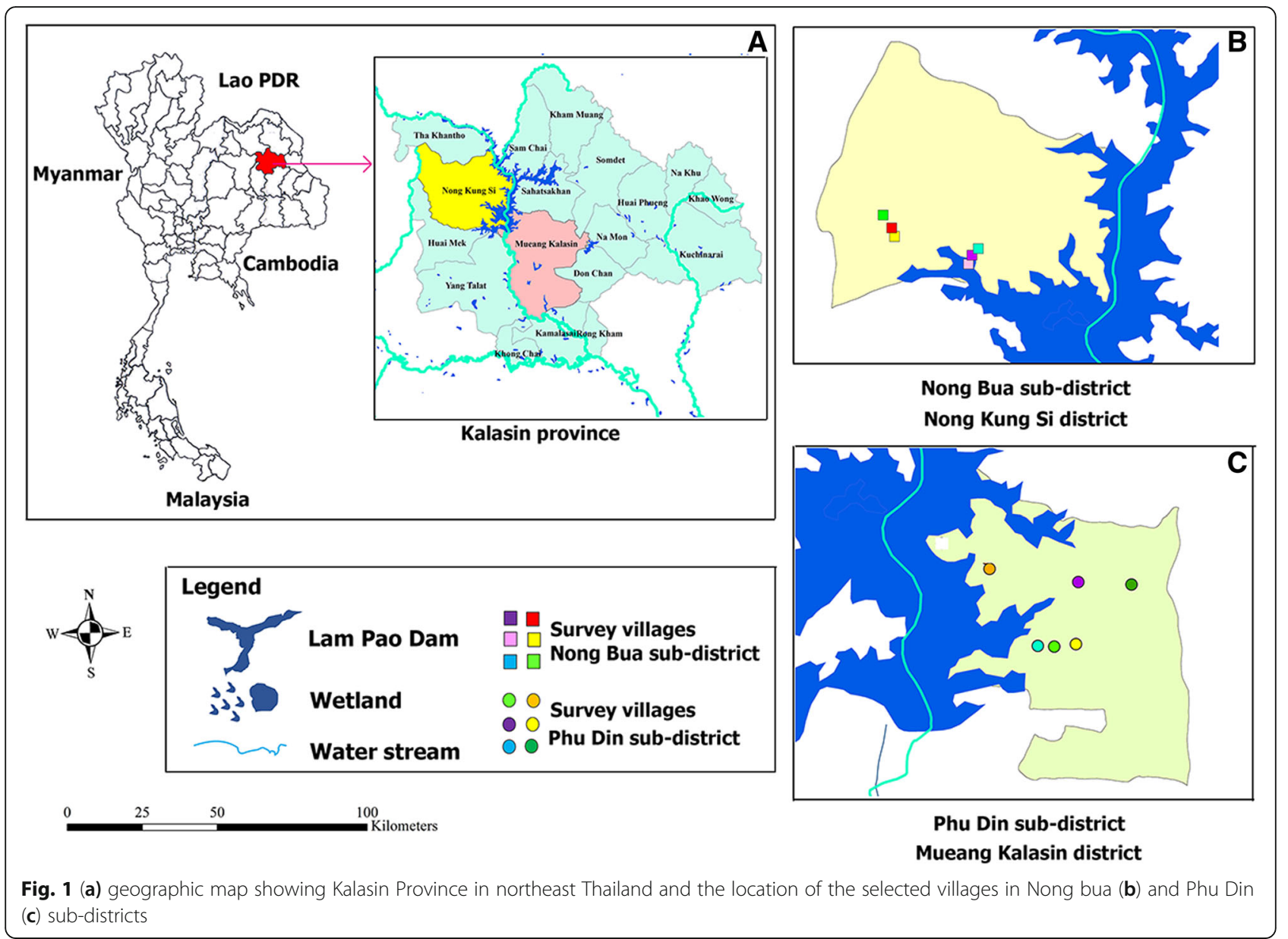

from other areas or 2) dropped out of the study. Subsequently, they were given plastic containers for stool collection with instructions. In the end, a total of 689 subjects returned stool specimens, 349 from the six villages in the intervention group and 340 from the six villages in the control group (Fig. 2).

\section{Baseline data collection and empirical methods}

Baseline data collection included screening for eligibility and S. stercoralis infection diagnosis, as well as data from a questionnaire assessing participants' knowledge and behavior with regard to S. stercoralis infection (see Additional file 1). The collection of data regarding demographic, socioeconomic, and environmental factors was conducted between January and May 2017. All participants who were infected with $S$. stercoralis underwent treatment and a subsequent follow-up 21-28 days post treatment (in June 2017). An intervention study was then initiated to evaluate the efficacy of the Health Education and Preventive Equipment Package (HEPEP) on September 2017 (Fig. 2).

\section{Questionnaire}

After giving written consent, research participants were interviewed in person at their homes using a three-part questionnaire which is developed for the present study. The first part consisted of demographic, socioeconomic, and environmental data; habits; and health status. The second part revolved around knowledge regarding S. stercoralis consisting of 15 questions. The questions in the second part were designed to test respondents' knowledge regarding S. stercoralis (biology, transmission, symptoms, prevention, and control). The knowledge score was interpreted based on the method employed by Bloom et al. [19]: 13-15 $(>80.00 \%)=$ high level of knowledge, 10-12 $(60.01-79.99 \%)=$ moderate level of knowledge, and 0-9 $(0.00$ to $60.00 \%)=$ low level of knowledge. According, the third part revolved around risk behaviors to S. stercoralis infection.

\section{Stool examination}

Stool samples were collected at baseline, follow-up (2128 days post treatment), and 3 months later in both the control and intervention groups. Clean plastic containers 


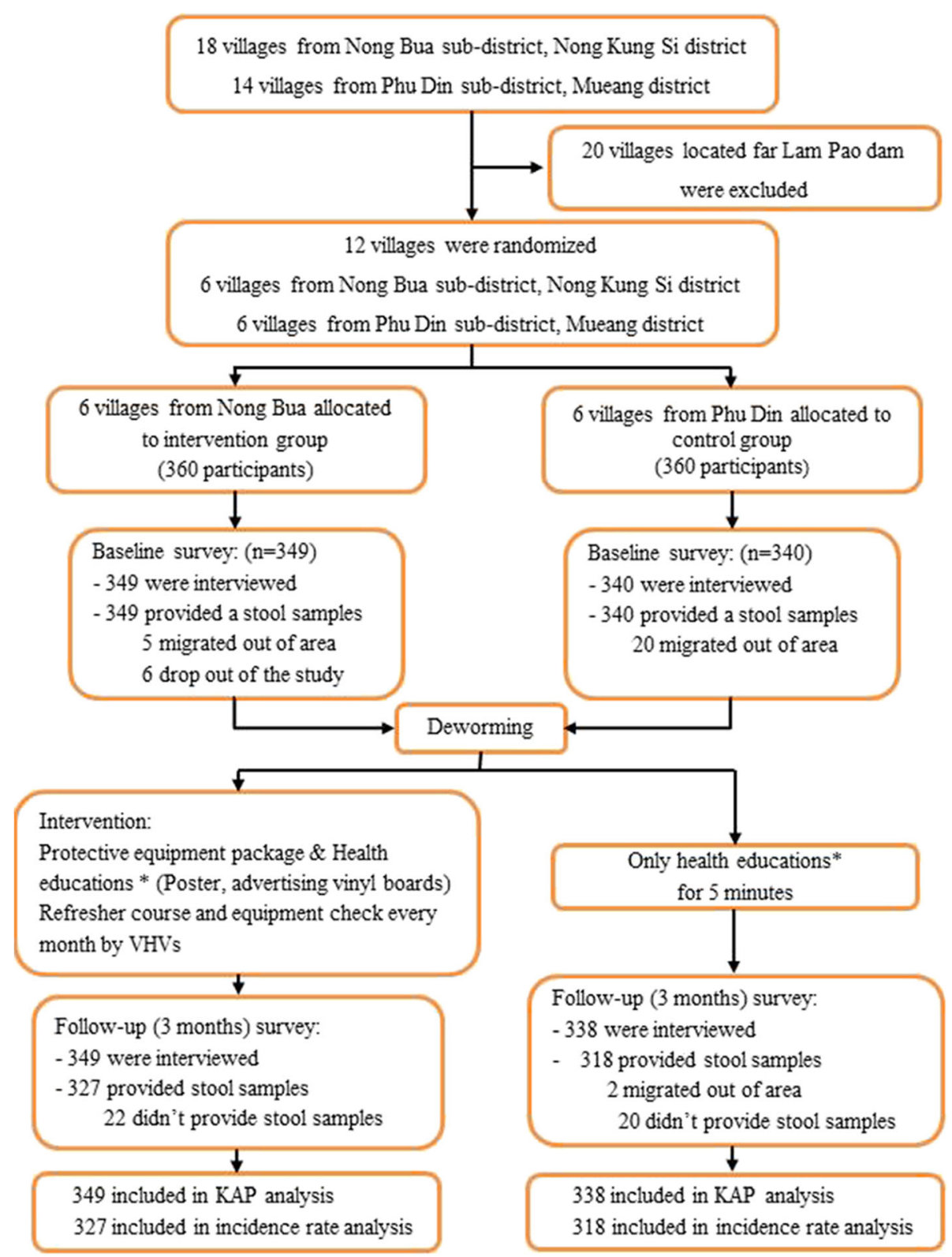

Fig. 2 Flow chart of the study's activities and follow up. *Health education program different between intervention group and control group. KAP: A Knowledge, Attitude and Practices; VHVs: Village health volunteers

labeled with the participants' names and code numbers were distributed to all participants by VHVs in each village. On the following day, the full containers were returned to the field staff who performed agar plate culture (APC), as described by Koga et al. [20], for detection of $S$. stercoralis infection. Two to 3 grams of stool was added to $1 \%$ nutrient agar in a plate that was $9 \mathrm{~cm}$ in diameter. The agar plate was incubated at 25-27 C for 35 days in a dark box and was examined under a stereomicroscope on either the third or fifth day [20]. The plates were transported to the Parasitology laboratory at the
Khon Kaen University Faculty of Medicine and observed under a stereomicroscope by qualified parasitologists. A negative result was recorded when $S$. stercoralis was not detected within 5 days of incubation.

\section{Deworming}

At baseline, follow-up, and three-months, participants who were infected with $S$. stercoralis were listed accordingly and received ivermectin $(200 \mu \mathrm{g} / \mathrm{Kg}$ body weight, single dose; Atlantic Laboratories Corporation Ltd., Samut Prakan, Thailand). All participants were administered the 
medication under observation by a researcher and medical officer. There were no complaints from the participants during ivermectin administration.

\section{Preventive equipment package and follow up}

Health education was provided to participants in both groups, but the intervention group was provided with a preventive equipment package (gloves and boots) and detailed information regarding $S$. stercoralis in the form of a "Practices to Prevent Strongyloidiasis" poster (size $29 \times 40 \mathrm{~cm}$ ) to be hung in participants' houses (see Additional file 2), vinyl boards containing information on $S$. stercoralis and strongyloidiasis (size $2 \times 3 \mathrm{~m}$ ) to be posted in each village (see Additional file 3), and a "S. stercoralis Life Cycle" poster (size $90 \times 120 \mathrm{~cm}$ ) (see Additional file 4) with a 20-min lecture explaining its contents. Subsequently, the intervention group was given a refresher course and their use of the equipment that was provided was checked every month by village health volunteers (VHVs). The control group was provided with only a five-minute lecture regarding human $S$. stercoralis infection. The participants from both areas were given follow-up S. stercoralis examinations and interviewed over the following 3 months (Fig. 2). The HEPEP-related follow-ups consisted of monthly visits to the villages in question by researchers and VHVs to observe the participants' practices with regard to wearing shoes and gloves while working on their farms (see Additional file 5). In addition, the VHVs reminded the participants about $S$. stercoralis transmission monthly via a broadcast tower in each village (Fig. 2).

\section{Statistical analysis}

Frequency, percentage, mean, and standard deviation (SD) were used to describe demographic characteristics. Prevalence of S. stercoralis infection was described in terms of proportion and 95\% confidence interval (95\% CI). To investigate the impact of Health Education and Protective Equipment Package on S. stercoralis infection, the prevalence of $S$. stercoralis infection in the intervention group and that in the control group were compared using logistic regression and a generalized estimating equation (GEE). To investigate the impact of the Health Education and Protective Equipment Package on knowledge scores, knowledge scores at baseline and 3 months were compared using pair $t$-test. To investigate the impact of the Health Education and Protective Equipment Package on behavior in each group, behavior at baseline and 3 months were compared using a paired McNemar's test. For adjusting possible confounders, all variables with a $P$-value less than 0.1 in the univariate analysis were selected. Additionally, the knowledge scores in the intervention and the control group were compared using a $t$-test. A P-value of less than 0.05 was considered statistically significant. The statistical analysis was conducted using the STATA package version 10.1 (College Station, Texas: StataCorp LLC).

\section{Results}

\section{Demographic characteristics}

A total of 689 study participants, 349 from Nong Bua sub-district (intervention group) and 340 from Phu Din sub-district (control group), were enrolled in the study. Three hundred twenty-three $(46.88 \%)$ of the participants were male and $366(53.12 \%)$ were female. The mean age $( \pm S D)$ was $51.19( \pm 12.04)$ years (range $=20-87$ years $)$. Four hundred sixty-seven of the participants $(67.77 \%)$ had graduated from primary school and $472(68.51 \%)$ were agriculturists. Most of the participants and household income lower than $\$ 250$ per month (according to the exchange rate as of 1 Nov 2017; 564 participants; $81.86 \%$ ) (\$250 per month is the poverty line in Thailand) [21]. The average household income $( \pm \mathrm{SD})$ was $\$ 167.54( \pm 214.15)$ (range $=0$ $1757.58 \$)$. Most of the participants $(495 ; 71.84 \%)$ were healthy. Larva currens were observed on the skin of 14 participants $(2.03 \%)$. With regard to participants' residential environments, 441 (64.01\%) reported damp soil around their houses and 494 (71.70\%) had one or more pets. Most of the participants $(688$; 99.85\%) used a cesspool and septic tank cleaner for feces management (Table 1).

Two hundred seventy-eight of 689 the participants (40.35\%) had adequate knowledge regarding $S$. stercoralis infection. The overall average knowledge score at baseline assessment was $71.69 \pm(14.48$; range $=0-100)$, with an average score of $73.81( \pm 11.11$; range $=40-100)$ in the intervention group and $69.51( \pm 17.03$; range $=0$ 93.33) in the control group (Table 1). In terms of participant behavior, 644 (93.46\%) had direct contact with soil, $423(65.68 \%)$ of whom had contact with soil in the area in which they farmed. Additionally, 540 participants (78.37\%) used animal dung as fertilizer. One hundred fifty-five $(22.50 \%)$ had used steroid drugs in the past. Importantly, 508 participants $(73.73 \%)$ reported that they sometimes defecated into the surrounding environment, rather than using a latrine (Table 1). Differences in age, occupation, underlying diseases, presence of a pet in the house, area in which there was direct contact with soil, and use of animal dung fertilizers were statistically significant between participants in the intervention area and the control area (Table 1).

\section{Prevalence of S. stercoralis infection at baseline}

Two hundred twenty-six (32.80\%; 95\%CI: 29.29 to 36.32) of the participants were found to be positive for $S$. 
Table 1 Baseline characteristic of participants in the intervention (HEPEP) and control group

\begin{tabular}{|c|c|c|c|c|}
\hline \multirow[t]{2}{*}{ Variables } & \multirow{2}{*}{$\begin{array}{l}\text { Intervention }(n=349) \\
\text { Number }(\%)\end{array}$} & \multirow{2}{*}{$\begin{array}{l}\text { Control }(n=340) \\
\text { Number }(\%)\end{array}$} & \multirow{2}{*}{$\begin{array}{l}\text { Total }(n=689) \\
\text { Number }(\%)\end{array}$} & \multirow{2}{*}{$\begin{array}{l}P \text {-value for tests of } \\
\text { between-group difference }\end{array}$} \\
\hline & & & & \\
\hline \multicolumn{5}{|l|}{ Individual characteristic } \\
\hline \multicolumn{4}{|l|}{ Gender } & \multirow[t]{3}{*}{0.058} \\
\hline Male & $176(50.43)$ & $147(43.24)$ & $323(46.88)$ & \\
\hline Female & $173(49.57)$ & $193(56.76)$ & $366(53.12)$ & \\
\hline \multicolumn{4}{|l|}{ Age } & \multirow[t]{2}{*}{$<0.001$} \\
\hline Mean \pm SD (Min:Max) & $49.40 \pm 11.81(20: 78)$ & $53.03 \pm 12.01(20: 87)$ & $51.19 \pm 12.04(20: 87)$ & \\
\hline \multicolumn{4}{|l|}{ Education levels } & \multirow[t]{7}{*}{0.177} \\
\hline Graduated or higher & $14(4.01)$ & $17(5.00)$ & $31(4.50)$ & \\
\hline Diploma & $7(2.01)$ & $8(2.35)$ & $15(2.18)$ & \\
\hline Grade 10-12 & $56(16.04)$ & $37(10.88)$ & $93(13.50)$ & \\
\hline Grade 7-9 & $36(10.32)$ & $32(9.41)$ & $68(9.87)$ & \\
\hline Primary school & $232(66.47)$ & $235(69.12)$ & $467(67.77)$ & \\
\hline No formal education & $4(1.15)$ & $11(3.24)$ & $15(2.18)$ & \\
\hline \multicolumn{4}{|l|}{ Occupations } & \multirow[t]{6}{*}{$<0.001$} \\
\hline Trade/ business owner & $28(8.02)$ & $103(30.29)$ & $131(19.01)$ & \\
\hline Government/private officer & $13(3.72)$ & $21(6.18)$ & $34(4.93)$ & \\
\hline Student & $1(0.29)$ & $1(0.29)$ & $2(0.29)$ & \\
\hline Agriculturalist & 298 (85.39) & $174(51.18)$ & $472(68.51)$ & \\
\hline Other (Elderly/Housewife) & $9(2.58)$ & $41(12.06)$ & $50(7.26)$ & \\
\hline \multicolumn{4}{|l|}{ BMI } & \multirow[t]{5}{*}{0.089} \\
\hline$<18.50$ & $19(5.44)$ & $31(9.12)$ & $50(7.26)$ & \\
\hline 18.50 to 24.99 & $199(57.02)$ & $171(50.29)$ & $370(53.70)$ & \\
\hline 25.00 to 29.99 & $108(30.95)$ & $121(35.59)$ & 229 (33.24) & \\
\hline$\geq 30.00$ & $23(6.59)$ & $17(5.00)$ & $40(5.80)$ & \\
\hline Mean \pm SD (Min: Max) & $24.10 \pm 3.81$ (15.06: 36.72) & $23.94 \pm 4.07(13.12: 44.82)$ & $24.02 \pm 3.94(13.12: 44.82)$ & 0.608 \\
\hline \multicolumn{4}{|l|}{ Household income (\$) } & \multirow[t]{3}{*}{0.393} \\
\hline$<250 \$$ & $290(83.10)$ & $274(80.59)$ & $564(81.86)$ & \\
\hline$\geq 250 \$$ & $59(16.90)$ & $66(19.41)$ & $125(18.14)$ & \\
\hline Mean \pm SD (Min:Max) & $160.42 \pm 199.15(0: 1696.97)$ & $174.86 \pm 228.58(0: 1757.58)$ & $167.54 \pm 214.15(0: 1757.58)$ & 0.377 \\
\hline \multicolumn{4}{|l|}{ Marital status } & \multirow[t]{4}{*}{0.71} \\
\hline Single & $14(4.01)$ & $16(4.71)$ & $30(4.35)$ & \\
\hline Married & $312(89.40)$ & $306(90.00)$ & $618(89.70)$ & \\
\hline Devoted & $23(6.59)$ & $18(5.29)$ & $41(5.95)$ & \\
\hline \multicolumn{4}{|l|}{ Underlying diseases } & \multirow[t]{3}{*}{0.006} \\
\hline No & $267(76.50)$ & $228(67.06)$ & $495(71.84)$ & \\
\hline Yes & $82(23.50)$ & $112(32.94)$ & $194(28.16)$ & \\
\hline \multicolumn{4}{|l|}{ Larvae currens } & \multirow[t]{3}{*}{0.961} \\
\hline No & 342 (97.99) & $333(97.94)$ & $675(97.97)$ & \\
\hline Yes & $7(2.01)$ & $7(2.06)$ & $14(2.03)$ & \\
\hline \multicolumn{5}{|l|}{ Residential environment } \\
\hline $\begin{array}{l}\text { Has damp soil around } \\
\text { house area }\end{array}$ & & & & 0.372 \\
\hline
\end{tabular}


Table 1 Baseline characteristic of participants in the intervention (HEPEP) and control group (Continued)

\begin{tabular}{|c|c|c|c|c|}
\hline \multirow[t]{2}{*}{ Variables } & \multirow{2}{*}{$\begin{array}{l}\text { Intervention ( } n=349) \\
\text { Number }(\%)\end{array}$} & \multirow{2}{*}{$\begin{array}{l}\text { Control }(n=340) \\
\text { Number }(\%)\end{array}$} & \multirow{2}{*}{$\begin{array}{l}\text { Total }(n=689) \\
\text { Number }(\%)\end{array}$} & \multirow{2}{*}{$\begin{array}{l}P \text {-value for tests of } \\
\text { between-group difference }\end{array}$} \\
\hline & & & & \\
\hline No & $120(34.38)$ & $128(37.65)$ & $248(35.99)$ & \\
\hline Yes & $229(65.62)$ & $212(62.35)$ & $441(64.01)$ & \\
\hline Flooding in area & & & & 0.834 \\
\hline No & $341(97.71)$ & 333 (97.94) & $674(97.82)$ & \\
\hline Yes & $8(2.29)$ & $7(2.06)$ & $15(2.18)$ & \\
\hline Presence of pet in house & & & & $<0.001$ \\
\hline No & $125(35.82)$ & $70(20.59)$ & $195(28.30)$ & \\
\hline Yes & $224(64.18)$ & $270(79.41)$ & $494(71.70)$ & \\
\hline Type of toilet & & & & 0.311 \\
\hline Cesspool & $349(100.00)$ & 339 (99.71) & $688(99.85)$ & \\
\hline Pit latrines & $0(0.00)$ & $1(0.29)$ & $1(0.15)$ & \\
\hline Feces management & & & & 0.311 \\
\hline Septic tank cleaner & $349(100.00)$ & 339 (99.71) & $688(99.85)$ & \\
\hline Fertilizer & $0(0.00)$ & $1(0.29)$ & $1(0.15)$ & \\
\hline \multicolumn{5}{|l|}{ Knowledge scores ${ }^{a}$} \\
\hline Poor (0.00 to 60.00) & $59(16.91)$ & $85(25.00)$ & $144(20.90)$ & 0.007 \\
\hline Moderate (60.01 to 79.99$)$ & $132(37.82)$ & $135(39.71)$ & $267(38.75)$ & \\
\hline Good (80.00 to 100.00) & $158(45.27)$ & $120(35.29)$ & $278(40.35)$ & \\
\hline Mean \pm SD (min:max) & $73.81 \pm 11.11(40.00: 100.00)$ & $69.51 \pm 17.03(0: 93.33)^{a}$ & $71.69 \pm 14.48(0.00: 100.00)^{a}$ & $<0.001$ \\
\hline \multicolumn{5}{|l|}{ Behaviors } \\
\hline Direct contact with soil & & & & 0.099 \\
\hline No & $17(4.87)$ & $28(8.24)$ & $45(6.53)$ & \\
\hline Yes & $332(95.13)$ & 312 (91.76) & $644(93.46)$ & \\
\hline $\begin{array}{l}\text { Area in which bare feet come } \\
\text { in contact with soil }\end{array}$ & $n=332$ & $n=312$ & $n=644$ & $<0.001$ \\
\hline Own Residence & $63(18.97)$ & $122(39.10)$ & $185(28.73)$ & \\
\hline Own Farm & $255(76.81)$ & $168(53.85)$ & $423(65.68)$ & \\
\hline Others' farms & $14(4.22)$ & $22(7.05)$ & $36(5.59)$ & \\
\hline Use of animal fertilizer & & & & 0.007 \\
\hline No & $61(17.48)$ & $88(25.88)$ & $149(21.63)$ & \\
\hline Yes & $288(82.52)$ & $252(74.12)$ & $540(78.37)$ & \\
\hline Steroid use & & & & 0.014 \\
\hline No & $284(81.38)$ & $250(73.53)$ & $534(77.50)$ & \\
\hline Yes & 65 (18.62) & $90(26.47)$ & $155(22.50)$ & \\
\hline $\begin{array}{l}\text { Defecation into surrounding } \\
\text { environment }\end{array}$ & & & & $<0.001$ \\
\hline No & $57(16.33)$ & $124(36.47)$ & $181(26.27)$ & \\
\hline Yes & $292(83.67)$ & $216(63.53)$ & $508(73.73)$ & \\
\hline
\end{tabular}

${ }^{a}$ Number of participants in the control group $=338$ at 3-month assessment and number of total participants $=687$

${ }^{b}$ Number of participants followed by the participants who came into direct contact with soil

stercoralis infection according to APC (Fig. 3). The positive rate was higher in male $(21.92 \%)$ than in female $(10.88 \%)$ participants. The peak infection rate was found in $40-59$ year-old participants (19.30\%) (Fig. 3). The baseline prevalence of $S$. stercoralis infections in the intervention group and the control group were comparable $31.23 \%$ (95\%CI: 26.40 to 36.38 ) and $34.41 \%$ (95\%CI: 29.37 to 39.73$)$, respectively with no statistically significant difference (Fig. 3). Twenty-eight days after treatment (follow-up), individual fecal samples of all 

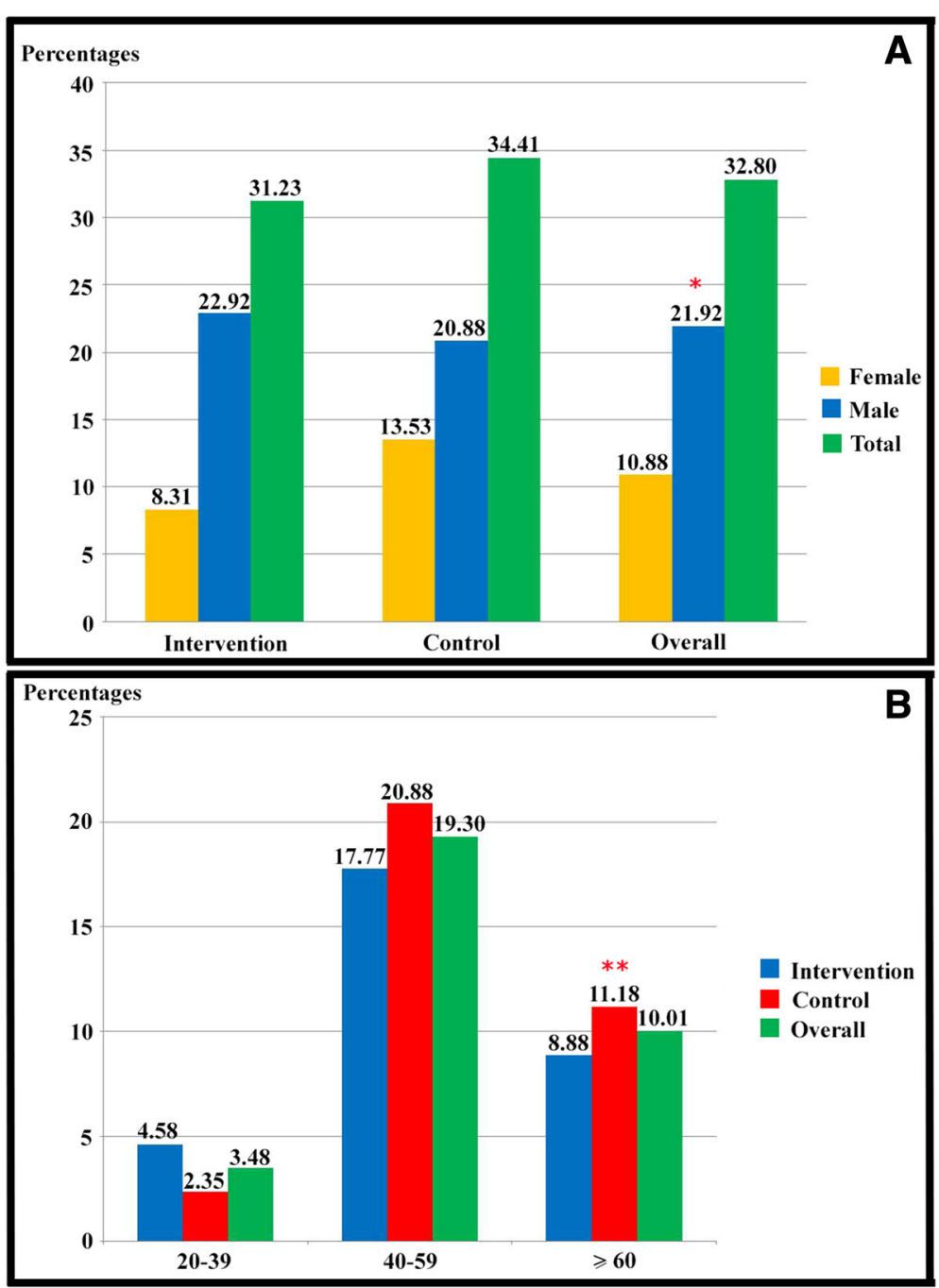

Fig. 3 Prevalence of S. stercoralis infection at the baseline assessment (a) prevalence of S. stercoralis infection at the baseline assessment classified by sex, (b) prevalence of $S$. stercoralis infection at the baseline assessment classified by age groups ${ }^{*}$ Statistically significant difference, $P$-value $<0.001^{* *}$ Statistically significant difference, $P$-value $<0.05$

participants were examined using APC. The prevalence of S. stercoralis infection had been reduced to $0 \%$ in both groups.

\section{Impact of the health education and preventive} equipment package on the prevalence of $S$. stercoralis at a three-month assessment

Three months after treatment, all participants were examined for the presence of $S$. stercoralis infection using APC. The prevalence of $S$. stercoralis infection in the intervention group and that in the control group were $2.75 \%(9 / 327)$ (95\%CI: 1.27 to 5.16$)$ and $6.60 \%(21 / 318)$ (95\%CI: 4.13 to 9.92 ), respectively (Fig. 4). There was a statistically significant difference in the prevalence of $S$. stercoralis infection between the intervention group and control group. The efficacy of the HEPEP in the prevention of S. stercoralis infection was $60 \%$ according to univariable analysis (cOR 0.40 ; $95 \% \mathrm{CI}: 0.18$ to 0.89 , P-value $=0.02$ ) and $41 \%$ according to multivariable analysis (aOR 0.59 ; $95 \%$ CI: 0.41 to 0.85 , $P$-value $=0.005$; Fig. 4, Table 2).

\section{Impact of the health education and preventive} equipment package on the knowledge of the participants in both groups

The knowledge of the participants from both groups was assessed at baseline and 3 months after starting the intervention study. The average knowledge scores in the intervention was statistically significant higher at 3 months than at baseline $(83.82[ \pm 10.35]$ vs $73.81[ \pm 11.11]$; mean difference [mean dif.] $=10.01,95 \%$ CI: 8.58 to 11.44 , $P$-value $=<0.001$; Table 3). Participants in the control 


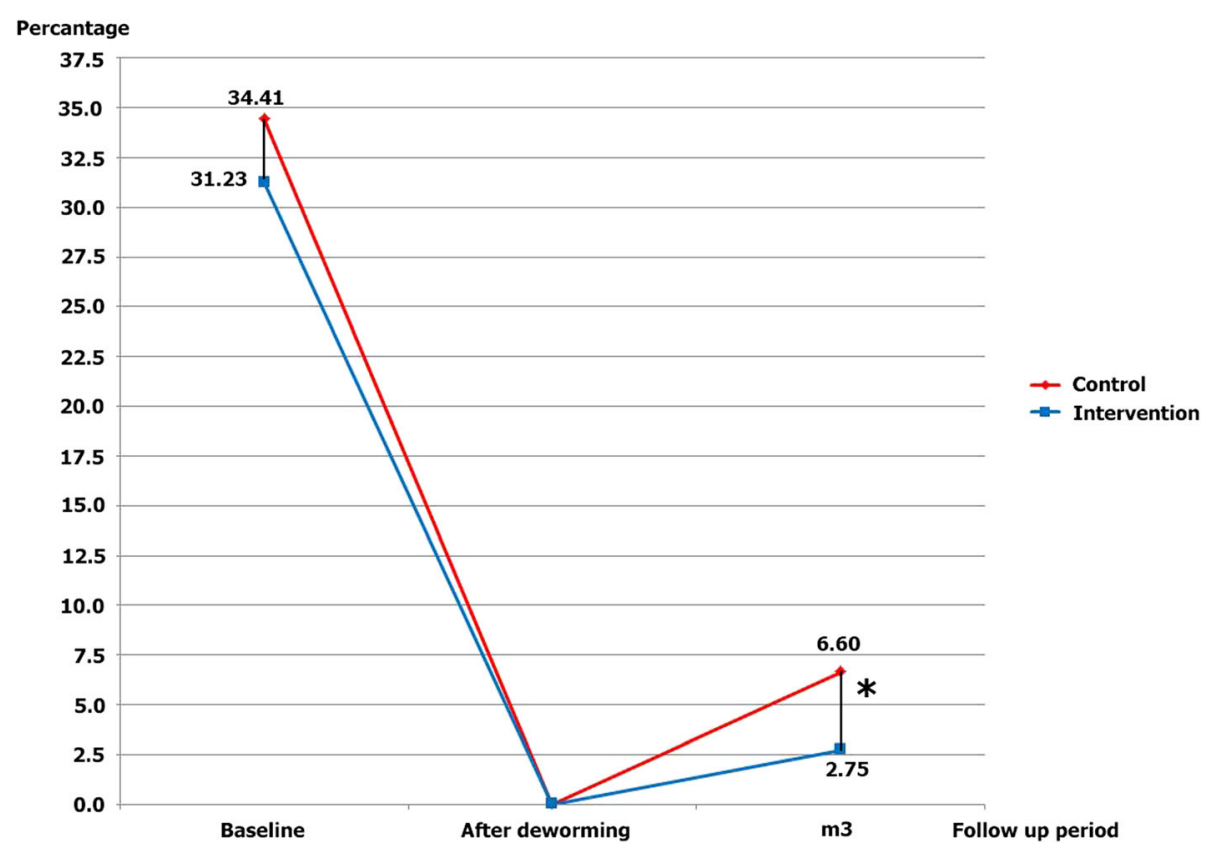

Fig. 4 Prevalence and incidence of S. stercoralis infection among the intervention and control groups. *Statistically significant difference, $P$-value $<0.05$

group also had a significantly higher knowledge score at 3 months than at baseline $(76.63[ \pm 13.02]$ vs $69.51[ \pm 17.03]$; mean dif. $=7.12,95 \%$ CI: 5.12 to 9.12 P-value $=<0.001$; Table 3). In terms of comparison between the two groups, the intervention group had a significantly higher increase in average knowledge score $(10.01[ \pm 0.73])$ than the control group $(7.12[ \pm 1.02])$ at 3 months (mean dif. $=2.89$, 95\%CI: 0.45 to 5.33, $P$-value $=0.021$; Table 3 ).

\section{Impact of the health education and preventive} equipment package on the behavior of participants at three months post-intervention

After starting the intervention, the increased knowledge scores of participants in the intervention group translated into behavioral changes in the areas of direct soil contact, use of animal dung fertilizer, use of steroid drugs, and defecation into the surrounding environment (Table 4). In the intervention group, the participants

Table 2 Effect of the health education and protective equipment package on prevalence of $\mathrm{S}$. stercoralis infection at three-month assessment using a generalized estimating equation (GEE)

\begin{tabular}{lll}
\hline Outcome variable & $\begin{array}{l}\text { Unadjusted } \\
\text { cOR }(95 \% \mathrm{Cl})\end{array}$ & $\begin{array}{l}\text { Adjusted } \\
\mathrm{aOR}^{\mathrm{a}}(95 \% \mathrm{Cl})\end{array}$ \\
\hline S. stercoralis prevalence & $0.40(0.18 \text { to } 0.89)^{* *}$ & $0.59(0.41 \text { to } 0.85)^{* *}$
\end{tabular}

Remark: adds ratios adjusted for sex, age, education level, occupation, household income (\$), underlying diseases, history of larva currens, presence of a pet in the house, direct contact with soil, use of animal fertilizer, and baseline $S$. stercoralis prevalence

**Statistically significant difference, $P$-value $<0.05$ were significantly less likely to have direct contact with soil (mean dif. $=8.88$; $95 \%$ CI: 4.70 to 13.07 ), use animal dung fertilizer (mean dif. $=51.86 ; 95 \%$ CI: 45.76 to 57.96), use steroid drugs (mean dif. $=7.45 ; 95 \%$ CI: 2.26 to 12.63), or defecate into the surrounding environment (mean dif. $=27.51 ; 95 \% \mathrm{CI}: 21.56$ to 33.45$)$ compared with the baseline assessment (Table 4). The increased knowledge scores in the control group translated into behavioral changes in the areas of direct soil contact, use of animal dung fertilizer, use of steroid drugs, and defecation into the surrounding environment (Table 4). At the follow-up, participants in the control group were significantly less likely to have direct contact with soil (mean dif. $=6.21 ; 95 \% \mathrm{CI}: 1.75$ to 10.68$)$, use animal dung fertilizer (mean dif. $=37.27 ; 95 \% \mathrm{CI}$ : 31.04 to 43.52 ), use steroid drugs (mean dif. $=8.29 ; 95 \% \mathrm{CI}$ : 2.68 to 13.88), or defecate into the surrounding environment (mean dif. $=31.06 ; 95 \% \mathrm{CI}$ : 24.79 to 37.34 ) compared with the baseline assessment (Table 4). Changes with regard to participants' use of steroid drugs and whether or not they defecated into the surrounding environment differed significantly between the intervention and control group at 3 months post-intervention (Table 4).

\section{Discussion}

The Health Education and Preventive Equipment Package (HEPEP) in this study demonstrated a $41 \%$ efficacy in the interruption S. stercoralis infection and transmission in a rural community in northeast Thailand. The reduction in the infection rate was correlated with 
Table 3 Strongyloides stercoralis knowledge scores at baseline and follow-up (three-month assessment post-deworming)

\begin{tabular}{|c|c|c|c|}
\hline \multirow[t]{2}{*}{ Variables } & Intervention $(n=349)$ & Control $(n=338)$ & $\begin{array}{l}\text { Mean difference between } \\
\text { group difference }\end{array}$ \\
\hline & Mean (SD) & Mean (SD) & Mean $(95 \% \mathrm{Cl})$ \\
\hline \multicolumn{4}{|l|}{ Baseline assessment } \\
\hline Knowledge scores & $73.81(11.11)$ & $69.51(17.03)$ & $4.24(2.15 \text { to } 6.45)^{*}$ \\
\hline \multicolumn{4}{|l|}{3 month assessment } \\
\hline Knowledge scores & $83.82(10.35)$ & $76.63(13.02)$ & $7.19(5.43 \text { to } 8.95)^{*}$ \\
\hline Mean difference between baseline and 3 month difference ${ }^{b}$ & $10.01(0.73)$ & $7.12(1.02)$ & $2.89(0.44 \text { to } 5.33)^{* *}$ \\
\hline
\end{tabular}

*Statistically significant difference, $P$-value $<0.001$

**Statistically significant difference, $P$-value $<0.05$

${ }^{a}$ Compared knowledge scores between intervention group and control group using t-test

${ }^{\mathrm{b}} \mathrm{C}$ mpared knowledge scores between baseline and three-month assessment within intervention group and control group using Pair t-test

increased knowledge scores and improvements in personal hygiene practices. Additionally, this is the first effective model of $S$. stercoralis control in adults in a rural community in Thailand. This result was similar to those of other studies that examined control of soil-transmitted helminthes in children [22-24].

At baseline, $32.80 \%$ of the participants were found to have $S$. stercoralis infection, which was higher than in previous studies [12-15, 25-28]. Variations in examination techniques, environmental sanitation, socioeconomic factors, and education levels of the participants likely contributed to this difference [29-31]. Participants aged $40-59$ years had a $19.30 \%$ prevalence of S. stercoralis infection, which was higher than in other age groups. Older adults have been shown to be at higher risk for $S$. stercoralis infection due to their having been exposed to contaminated soil over a longer period of time [2, 28].

At the three-month assessment, the prevalence of $S$. stercoralis infection had increased from $0 \%$ (after deworming) to $2.75 \%$ in the intervention group. In addition, the prevalence of $S$. stercoralis infection in the control group (the participants in which were provided with only a five-minute lecture) had increased from $0 \%$ (after deworming) to $6.60 \%$. This study found that the HEPEP was effective in preventing S. stercoralis infection.

Although nearly all participants in both groups had flush latrines (cesspool) in their house (99.85\%), the prevalence of $S$. stercoralis infection was still high. This suggests that improvement to sanitation infrastructure alone would not be sufficient to reduce the prevalence of S. stercoralis infection, as residents do not always use a latrine [32, 33]. Most of the participants were agriculturists and defecated into surrounding environment while working on their farm. As has been previously reported in Vietnam and Lao PDR, the presence of latrines alone is not sufficient to decrease the prevalence of helminthiasis in rural communities if fresh feces are used as fertilizer [34]. Furthermore, a lack of knowledge regarding $S$. stercoralis transmission is an important factor that increases S. stercoralis transmission among participants.

Table 4 Behavior factors at 3 months assessment after starting a full health education program in the intervention group and receiving a lecture in the control group

\begin{tabular}{|c|c|c|c|c|c|c|c|}
\hline \multirow[t]{3}{*}{ Behaviors } & \multicolumn{3}{|l|}{ Intervention } & \multicolumn{3}{|l|}{ Control } & \multirow{3}{*}{$\begin{array}{l}\text { Odds Ratios }(95 \% \mathrm{Cl}) \\
\text { Compare between } \\
\text { intervention and control } \\
\text { group at } 3 \text { month }{ }^{c}\end{array}$} \\
\hline & $\begin{array}{l}\text { Baseline } \\
(n=349)\end{array}$ & $\begin{array}{l}3 \text { month } \\
(n=349)\end{array}$ & $\begin{array}{l}\text { Difference between } \\
\text { proportions }\end{array}$ & $\begin{array}{l}\text { Baseline } \\
(n=338)\end{array}$ & $\begin{array}{l}3 \text { month } \\
(n=338)\end{array}$ & $\begin{array}{l}\text { Difference between } \\
\text { proportions }\end{array}$ & \\
\hline & n (\%) & n (\%) & difference $(95 \% \mathrm{Cl})^{a}$ & n (\%) & n (\%) & difference $(95 \% \mathrm{Cl})^{\mathrm{b}}$ & \\
\hline \multicolumn{8}{|c|}{ Directly contacted soil } \\
\hline Yes & $332(95.13)$ & $301(86.25)$ & $8.88(4.70 \text { to } 13.07)^{*}$ & $310(91.71)$ & $289(85.50)$ & $6.21(1.75 \text { to } 10.68)^{* *}$ & $0.94(0.61$ to 1.44$)$ \\
\hline \multicolumn{8}{|c|}{ Animal fertilizer use } \\
\hline Yes & $288(82.52)$ & $107(30.66)$ & $51.86(45.76 \text { to } 57.96)^{*}$ & $250(73.96)$ & $124(36.69)$ & $37.27(31.04 \text { to } 43.52)^{*}$ & $1.31(0.95$ to 1.78$)$ \\
\hline \multicolumn{8}{|c|}{ Steroid drug use } \\
\hline Yes & $65(18.62)$ & $39(11.17)$ & $7.45(2.26 \text { to } 12.63)^{* *}$ & $88(26.04)$ & $60(17.75)$ & $8.29(2.68 \text { to } 13.88)^{* *}$ & $1.71(1.11 \text { to } 2.65)^{* *}$ \\
\hline \multicolumn{8}{|c|}{ Defecation into surrounding environment } \\
\hline Yes & $292(83.67)$ & $196(56.16)$ & $27.51(21.56 \text { to } 33.45)^{*}$ & $214(63.31)$ & $109(32.25)$ & $31.06(24.79 \text { to } 37.34)^{*}$ & $0.37(0.27 \text { to } 0.51)^{*}$ \\
\hline
\end{tabular}

${ }^{a}$ Mean difference in intervention group between baseline and three-month assessment after deworming using pair McNemar's test

${ }^{\mathrm{b}}$ Mean difference in control group between baseline and three-month assessment after deworming using pair McNemar's test

${ }^{c}$ Compared between intervention and control group at 3 months using a chi-squared test

* Statistically significant difference, $P$-value $<0.001$

**Statistically significant difference, $P$-value $<0.05$ 
This study showed that the average knowledge score of participants in the intervention group (received HEPEP) at the three-month assessment was 2.89 points higher than that of participants in the control group. Furthermore, a high knowledge score was associated with a decrease in the prevalence of $S$. stercoralis infection and behavior changes that resulted in decreased infection, which was similar to the results of previous studies [22, 24]. However, the limitation of this study was its short duration (3 months of assessments). Thus, we plan to continue conducting research to assess the long-term effectiveness of the HEPEP (once per year).

\section{Conclusions}

The Health Education and Preventive Equipment Package (HEPEP) was developed and distributed to rural communities in Kalasin province in northeast Thailand as the first health education program aimed at controlling S. stercoralis infection in this region. The HEPEP proved effective, especially in terms of preventing S. stercoralis infection. The HEPEP may also be a useful model for controlling other soil-transmitted nematode parasites that infect humans via the same route, especially hookworms in endemic areas of southern Thailand.

Despite the implementation of an intensive national parasite control program in rural areas of northeast Thailand decades ago, strongyloidiasis is still highly prevalent and is sympatric with opisthorchiasis. The results of this study support the argument that there is an urgent need to start an integrated and effective S. stercoralis control program using the HEPEP supplemented with long-term follow-up.

\section{Additional files}

Additional file 1: Research Questionnaire, a questionnaire assessing participants' knowledge and behavior. (PDF $358 \mathrm{~kb}$ )

Additional file 2: Poster, a "Practices to Prevent Strongyloidiasis" poster. (TIF $1851 \mathrm{~kb}$ )

Additional file 3: Vinyl boards, a vinyl boards containing information on S. stercoralis and strongyloidiasis. (TIF $761 \mathrm{~kb}$ )

Additional file 4: Life Cycle poster, a "S. stercoralis Life Cycle" poster. (TIF $2012 \mathrm{~kb}$ )

Additional file 5: The HEPEP-related follow-ups, a: equipment package (gloves and boots), b: "practice to prevent strongyloidiasis" poster, c: Lecture activity of human strongyloidiasis prevention by using $S$. stercoralis life cycle poster, d: S. stercoralis and strongyloidiasis advertising vinyl boards containing information on S. stercoralis and strongyloidiasis to promote in each village, e and f: checked equipment using every month by village health volunteers and researchers. (TIF $5464 \mathrm{~kb}$ )

\section{Abbreviations}

95\%Cl: 95\% confidence interval; aOR: Adjusted Odds Ratio; APC: Agar plate culture; BMI: Body mass index; COR: Crude Odds Ratio; GEE: Generalized estimating equation; HEPEP: The Health Education and Preventive Equipment Package; mean dif:: Mean difference; SD: Standard deviation; VHVs: Village health volunteers; $\mu \mathrm{g} / \mathrm{Kg}$ : Microgram per kilogram

\section{Acknowledgements}

We wish to acknowledge the support of the English Consultation Clinic at the Khon Kaen University Faculty of Medicine Research Affairs Division and the Khon Kaen University Publication Clinic at the Research and Technology Transfer Affairs Division for their assistance. The authors would like to acknowledge the directors of Mueang District Public Health Office and Nong Kung Si District Public Health Office, and the directors of each sub-district health-promotion hospital for their support throughout the course of this study.

\section{Funding}

This study was supported by a TRF Senior Research Scholar Grant, Thailand Research Fund grant number RTA5880001; OS was supported by the Scholarship under the Post-Doctoral Training Program from Research Affairs and Graduate School, Khon Kaen University (58101). The findings and conclusions in this report are those of the authors and do not necessarily represent the official position of the funding agencies.

\section{Availability of data and materials}

The datasets generated and/or analyzed during the current study are not publicly available due to patient privacy but are available from the corresponding author on reasonable request.

\section{Authors' contributions}

$P L, W M, W K, R K$, and PM conceived of substantial contributions to conception and design, acquisition of data, and analysis and interpretation of data. PL, RR, OS, PM, WM, RK and TT conducted the study and involved in drafting the manuscript and revising it critically for important intellectual content. All authors read and approved the final manuscript.

\section{Ethics approval and consent to participate}

This study was approved by the Khon Kaen University Ethics Committee for Human Research (HE601048). All participants were informed of the study methods, risks, and benefits of the process. Written and signed or thumbprinted informed consent was obtained from participants before beginning the study.

\section{Consent for publication}

Not applicable.

\section{Competing interests}

The authors declare that they have no competing interests.

\section{Publisher's Note}

Springer Nature remains neutral with regard to jurisdictional claims in published maps and institutional affiliations.

\section{Author details}

'Department of Public Health Administration, Health Promotion, Nutrition, Faculty of Public Health, Khon Kaen University, Khon Kaen, Thailand. ${ }^{2}$ Department of Parasitology, Faculty of Medicine, Khon Kaen University, Khon Kaen, Thailand. ${ }^{3}$ Research and Diagnostic Center for Emerging Infectious Diseases, Khon Kaen University, Khon Kaen, Thailand. ${ }^{4}$ Faculty of Medicine, Mahasarakham University, Mahasarakham, Thailand. ${ }^{5}$ Department of Computer Engineering, Faculty of Engineering, Khon Kaen University, Khon Kaen, Thailand.

Received: 25 August 2018 Accepted: 1 October 2018

Published online: 19 October 2018

\section{References}

1. Grove DI. Human strongyloidiasis. Adv Parasitol. 1996;38:251-309.

2. Prasongdee TK, Laoraksawong P, Kanarkard W, Kraiklang R, Sathapornworachai K, Naonongwai S, et al. An eleven-year retrospective hospital-based study of epidemiological data regarding human strongyloidiasis in Northeast Thailand. BMC Infect Dis. 2017;17:627.

3. Jourdan PM, Lamberton PHL, Fenwick A, Addiss DG. Soil-transmitted helminth infections. Lancet. 2017. https://doi.org/10.1016/S0140-6736(17)31930-X.

4. WHO. Investing to overcome the global impact of neglected tropical diseases. In: Third WHO report on neglected tropical diseases. Geneva, World Health Organization; 2015. 
5. Puthiyakunnon S, Boddu S, Li Y, Zhou X, Wang C, Li J, et al. Strongyloidiasis--an insight into its global prevalence and management. PLoS Negl Trop Dis. 2014;8:e3018.

6. Olsen A, van Lieshout L, Marti H, Polderman T, Polman K, Steinmann P, et al. Strongyloidiasis--the most neglected of the neglected tropical diseases? Trans R Soc Trop Med Hyg. 2009;103:967-72.

7. Toledo R, Munoz-Antoli C, Esteban JG. Strongyloidiasis with emphasis on human infections and its different clinical forms. Adv Parasitol. 2015;88:165-241.

8. Schär F, Trostdorf U, Giardina F, Khieu V, Muth S, Marti H, et al. Strongyloides stercoralis: global distribution and risk factors. PLoS Negl Trop Dis. 2013;7:e2288.

9. Viney ME, Lok JB. The biology of Strongyloides spp. In: WormBook: the online review of C elegans biology; 2015. https://doi.org/10.1895/wormbook.1.141.2. Accessed 13 Aug 2018

10. Jongsuksuntigul P, Intapan PM, Wongsaroj T, Nilpan S, Singthong S, Veerakul S, et al. Prevalence of Strongyloides stercoralis infection in northeastern Thailand (agar plate culture detection). J Med Assoc Thail. 2003;86:737-41.

11. Jongwutiwes U, Waywa D, Silpasakorn S, Wanachiwanawin D, Suputtamongkol Y. Prevalence and risk factors of acquiring Strongyloides stercoralis infection among patients attending a tertiary hospital in Thailand. Pathog Glob Health. 2014;108:137-40.

12. Nontasut P, Muennoo C, Sa-nguankiat S, Fongsri S, Vichit A. Prevalence of Strongyloides in northern Thailand and treatment with ivermectin vs albendazole. Southeast Asian J Trop Med Public Health. 2005:36:442-4

13. Sithithaworn J, Sithithaworn P, Janrungsopa T, Suvatanadecha K, Ando K, Haswell-Elkins MR. Comparative assessment of the gelatin particle agglutination test and an enzyme-linked immunosorbent assay for diagnosis of strongyloidiasis. J Clin Microbiol. 2005;43:3278-82.

14. Sithithaworn P, Srisawangwong T, Tesana S, Daenseekaew W, Sithithaworn J, Fujimaki Y, et al. Epidemiology of Strongyloides stercoralis in north-East Thailand: application of the agar plate culture technique compared with the enzyme-linked immunosorbent assay. Trans Roy Soc Trop Med Hyg. 2003;97:398-402

15. Wongsaroj T, Nithikathkul C, Rojkitikul W, Nakai W, Royal L, Rammasut P. Brief Communication (Original). National survey of helminthiasis in Thailand. Asian Biomed. 2014:779.

16. WHO. Research priorities for helminth infections: technical report of the TDR disease reference group on helminth infections. In: Technical report series; no. 972. WHO Press: Geneva; 2012. p. 175.

17. Office of Agriculture Economics, Ministry of Agriculture and Cooperatives. 2016. http://www.oae.go.th/download/download_journal/2560/yearbook59.pdf. Accessed 6 Sept 2017. [In Thai].

18. Yahom S, Kullawat J, Boonsai D, Chatuphonprasert W, Thanchomnang T, Radomyos P. The prevalence of intestinal parasitic infections in Maha Sarakham and Kalasin provinces. J Trop Med Parasitol. 2013;36:29-33.

19. Bloom BS, Hastings JH, Madaus GF. Handbook on formative Evalution of student learning. New York: McGraw-hill; 1971.

20. Koga K, Kasuya S, Khamboonruang C, Sukhavat K, leda M, Takatsuka N, et al. A modified agar plate method for detection of Strongyloides stercoralis. Am J Trop Med Hyg. 1991;45:518-21.

21. The Secretariat of the Cabinet. Measures to increase income for low income people. https://www.mof.go.th/home/Press_release/News2016/154.pdf (2016). Accessed 16 Apr 2018. [In Thai].

22. Al-Delaimy AK, Al-Mekhlafi HM, Lim YA, Nasr NA, Sady H, Atroosh $W M$, et al. Developing and evaluating health education learning package (HELP) to control soil-transmitted helminth infections among orang Asli children in Malaysia. Parasit Vectors. 2014;7:416.

23. Bieri F, Gray DJ, Williams GM, Raso G, Li Y-S, Yuan L, et al. HealthEducation Package to Prevent worm infections in Chinese schoolchildren. N Engl J Med. 2013:368:1603-12.

24. Gyorkos TW, Maheu-Giroux M, Blouin B, Casapia M. Impact of health education on soil-transmitted helminth infections in schoolchildren of the Peruvian Amazon: a cluster-randomized controlled trial. PLoS Negl Trop Dis. 2013;7:e2397.

25. Boonjaraspinyo $S$, Boonmars T, Kaewsamut B, Ekobol N, Laummaunwai $P$, Aukkanimart $\mathrm{R}$, et al. A cross-sectional study on intestinal parasitic infections in rural communities, Northeast Thailand. Korean J Parasitol. 2013;51:727-34.

26. Intapan PM, Maleewong W, Wongsaroj T, Singthong S, Morakote N. Comparison of the quantitative formalin ethyl acetate concentration technique and agar plate culture for diagnosis of human strongyloidiasis. Clin Microbiol. 2005;43:1932-3.
27. Kitvatanachai S, Boonslip S, Watanasatitarpa S. Intestinal parasitic infections in Srimum suburban area of Nakhon Ratchasima Province, Thailand. Trop Biomed. 2008;25:237-42.

28. Wongsaroj T, Phatihatakorn W, Ramasoota P, Anamnart W, Kaewpoonsri N, Chiewchanyon B. Epidemiological study of strongyloidiasis in southern Thailand, 2007. J Trop Med Parasitol. 2008;31:6-13.

29. Hotez PJ, Brindley PJ, Bethony JM, King CH, Pearce EJ, Jacobson J. Helminth infections: the great neglected tropical diseases. J Clin Invest. 2008;118:1311-21.

30. Hotez PJ, Bundy DAP, Beegle K, Brooker S, Drake L, de Silva N, et al. Helminth Infections: Soil-transmitted Helminth Infections and Schistosomiasis. In: Jamison DT, Breman JG, Measham AR, Alleyne G, Claeson M, Evans DB, et al., editors. Disease Control Priorities in Developing Countries. Washington (DC): World Bank; 2006

31. Punsawad C, Phasuk N, Bunratsami S, Thongtup K, Siripakonuaong N, Nongnaul S. Prevalence of intestinal parasitic infection and associated risk factors among village health volunteers in rural communities of southern Thailand. BMC Public Health. 2017;17:564.

32. Arfaa F, Sahba GH, Farahmandian I, Jalali H. Evaluation of the effect of different methods of control of soil-transmitted helminths in Khuzestan, Southwest Iran. Am J Trop Med Hyg. 1977;26:230-3.

33. Asaolu SO, Ofoezie IE. The role of health education and sanitation in the control of helminth infections. Acta Trop. 2003:86:283-94.

34. Yajima A, Jouquet $P, D o T D$, Dang TC, Tran CD, Orange D, et al. High latrine coverage is not reducing the prevalence of soil-transmitted helminthiasis in Hoa Binh province, Vietnam. Trans R Soc Trop Med Hyg. 2009;103:237-41.

\section{Ready to submit your research? Choose BMC and benefit from:}

- fast, convenient online submission

- thorough peer review by experienced researchers in your field

- rapid publication on acceptance

- support for research data, including large and complex data types

- gold Open Access which fosters wider collaboration and increased citations

- maximum visibility for your research: over $100 \mathrm{M}$ website views per year

At BMC, research is always in progress.

Learn more biomedcentral.com/submissions 